\title{
Impactos econômicos e ambientais decorrentes do estado de conservação das rodovias brasileiras: um estudo de caso
}

Daniela Bacchi Bartholomeu ${ }^{1}$ José Vicente Caixeta Filho ${ }^{2}$

Resumo: Devido à importância do modal rodoviário para a economia brasileira no que diz respeito à sua participação na matriz de transporte de cargas, à elevada participação no consumo de combustíveis fósseis (óleo diesel) e nas emissões de $\mathrm{CO}_{2}$, este artigo avalia se rodovias em melhores estados de conservação implicam benefícios econômicos e ambientais. Os benefícios econômicos disseram respeito à avaliação dos seguintes parâmetros: consumo de combustível, tempo de viagem e gasto com manutenção do veículo. Já os benefícios ambientais referiram-se às reduções das externalidades negativas resultantes da diminuição nas emissões de $\mathrm{CO}_{2}$. Foram realizadas coletas de dados primários relacionados ao desempenho observado em caminhões (dotados de computadores de bordo para auxiliar na coleta dos dados) em rodovias com diferentes condições de infra-estrutura. Num total de 20 viagens realizadas, foram observados o consumo de combustível e o perfil das velocidades em duas rotas em diferentes estados de conservação (Campo Grande a Santos e Rondonópolis a Campo Grande). Os resultados indicaram a existência de benefícios econômicos e ambientais para as rotas em melhor estado de conservação.

\footnotetext{
${ }^{1}$ Doutora em Economia Aplicada pela Esalq/USP. E-mail: dbbartho@esalq.usp.br 2 Professor Titular do Departamento de Economia, Administração e Sociologia da Esalq/ USP. E-mail: jvcaixet@esalq.usp.br
} 
Impactos econômicos e ambientais decorrentes do estado de conservação das rodovias brasileiras: um estudo de caso

Palavras-chaves: Transporte rodoviário de cargas; Benefícios econômicos; Benefícios ambientais; Emissões de $\mathrm{CO}_{2}$

\section{JEL Classification: Q5}

Abstract: This article evaluates economic and environmental impacts of Brazilian highway conditions. The economic benefits evaluated were: diesel consumption, travel time and vehicle maintenance; the environmental benefits evaluated were the reduction on negative externalities related to decrease on carbon dioxide $\left(\mathrm{CO}_{2}\right)$ emissions. Primary computer collected data related to the trucks performances on highways with different infrastructure conditions. The data were derived from 20 trips over 2 routes, each route representative of one of two highway conditions: better or worse (Campo Grande to Santos, and Rondonópolis to Campo Grande). The results had confirmed economics and environmental benefits resulting from travel over the better routes.

\section{Introdução}

O transporte de cargas no Brasil é altamente dependente do modal rodoviário. Esta dependência excessiva fica evidente quando se verifica a participação deste modal em outros países de dimensões continentais. Enquanto no Brasil o transporte rodoviário movimenta cerca de $60 \%$ da matriz de transporte de cargas nacional, nos Estados Unidos, a participação das rodovias é de $26 \%$, na Austrália, de $24 \%$, e na China, de apenas 8\% (Centro de Estudos em Logística - CEL et al., 2002).

Conseqüentemente, o desempenho deste modo de transporte acaba sendo prejudicado. Comparado ao desempenho observado nos EUA, por exemplo, verifica-se que a produtividade do transporte rodoviário brasileiro é $22 \%$ inferior, enquanto o consumo energético e a emissão monóxido de carbono (em gCO/t.km) são 29\% e 2,6 vezes superiores à norte-americana (CEL et al., 2002).

Alguns dos aspectos que contribuem para o fraco desempenho do modal rodoviário no Brasil são: a elevada idade média da frota (os veículos - cerca de 1,5 milhão - possuem, em média, quase 16 anos) 
e uma oferta insuficiente de infra-estrutura de transporte rodoviária, tanto em termos de extensão quanto em termos de qualidade das vias.

Com relação à extensão, tomando-se como base o indicador de disponibilidade, medido pela relação "quilometragem total de rodovia por espaço territorial $\left(\mathrm{em} \mathrm{km}^{2}\right)$ ", a oferta de vias de transporte no Brasil é equivalente a $69 \%$ da verificada na China, $55 \%$ do Canadá, $45 \%$ do México, e $6 \%$ dos EUA (CEL et al., 2002).

Da oferta total de rodovias (cerca de 1,6 milhão de quilômetros), apenas $12 \%$ são pavimentadas (Boletim Estatístico CNT, 2005b). Da parcela estatal pavimentada analisada pela Pesquisa Rodoviária (CNT, 2005a), mais de 59 mil km, ou cerca de $72 \%$, encontram-se com pavimento classificados como “Deficiente”, "Ruim” ou "Péssimo”. A região Nordeste é a que detém as piores condições da malha rodoviária em todo o País, fato que compromete o desenvolvimento e as possibilidades de maior integração econômica com as demais regiões.

Estudos indicam que a má conservação das rodovias não somente impacta de forma negativa a economia, como gera um processo de "anti-economia", ou seja, o volume poupado em serviços de manutenção da qualidade no momento adequado resulta em acréscimos em gastos futuros com obras de reconstrução e em custos adicionais para os usuários das vias.

Estudo realizado por técnicos do Departamento Nacional de Estradas de Rodagem (DNER) e da Empresa Brasileira de Planejamento de Transportes (Geipot) apontam que uma estrada degradada representa aumento de $58 \%$ no consumo de combustíveis, de $38 \%$ nos gastos de manutenção de veículo, de 50\% no índice de acidentes e de até 100\% no tempo gasto nas viagens (Revista CNT, 2001, p.1).

O mau estado das rodovias tem impacto direto na economia. Relatórios da Comissão Econômica para a América Latina (Cepal) e do Banco Mundial estimam que ao mau estado da infra-estrutura viária na América Latina estão associados prejuízos de cerca de $2 \%$ do PIB, conforme documentado por IRF/GTZ (1996³), apud Senna et al. (1998).

\footnotetext{
${ }^{3}$ IRF/GTZ - International Road Federation/Deutusche Gesellschaft Für Technische Zusammenarbeit. Concessiones en Argentina. Reforma: Conservação Vial, n.1. Santiago de Chile. Julho, 1996.
} 
De acordo com o Boletim Estatístico CNT (2005b), os investimentos necessários para recuperação do pavimento da malha nacional (cerca de 55,6 mil km) totalizam $\mathrm{R} \$ 11,8$ bilhão. Este valor considera os gastos necessários com obras de manutenção das rodovias em "bom" estado, de restauração de rodovias consideradas "deficientes" ou "ruins" e reconstrução de rodovias em "péssimas” condições de conservação.

Pelo lado da receita do governo, a Lei $\mathrm{n}^{\circ}$ 10.336/2001 instituiu a Contribuição de Intervenção no Domínio Econômico (Cide), incidente sobre a importação e a comercialização de petróleo e seus derivados, gás natural e seus derivados e álcool etílico combustível, para que seus recursos fossem destinados, também, ao financiamento de programas de infra-estrutura de transportes. Segundo dados divulgados pelo Boletim Econômico CNT (CNT, 2006), entre 2002 e 2005 foram arrecadados cerca de $\mathrm{R} \$ 30$ bilhões com a Cide (uma média de $\mathrm{R} \$$ 7,5 bilhões por ano). Entretanto, o investimento total acumulado em transporte até 21 de janeiro de 2006 foi de apenas R\$ 8,9 bilhões (considerando investimentos em todos os modais de transporte).

Verifica-se que, apesar da destinação constitucional da Cide para investimentos na infra-estrutura de transportes, seus recursos foram essencialmente utilizados na formação do superávit primário do governo (CNT, 2006).

Finalmente, deve-se destacar também a elevada dependência do transporte rodoviário em relação aos combustíveis fósseis ${ }^{4}$, fato que torna este modo de transporte um importante consumidor de energia e, como resultado, faz deste setor o maior emissor de $\mathrm{CO}_{2}$ no Brasil. Considerando somente o modal rodoviário, este respondeu por $27 \%$ do consumo final de energia do Brasil em 2004 e por $92 \%$ do consumo final de energia pelo setor transporte. Dados do BEN apontam um crescimento de 39,2\% no consumo de energia do transporte rodoviário entre 1994 e 2004 (Brasil, 2005). A fonte de energia mais consumida foi o óleo diesel, responsável por aproximadamente $52 \%$ do consumo total. A taxa de crescimento do consumo de diesel no período foi de $42,4 \%$.

Em 1994, o subsetor “transportes” foi responsável por cerca de $40 \%$ das emissões de $\mathrm{CO}_{2}$ do setor "energia” no Brasil, de acordo com dados

${ }^{4}$ A partir de 1996, a totalidade dos caminhões vendidos no mercado interno era movido a diesel. 
da Comunicação Nacional, sendo o modal rodoviário responsável por quase $90 \%$ deste total (Brasil, 2004).

Este cenário torna importante a busca por opções que resultem em diminuições no consumo de combustível fóssil pelo modal rodoviário, reduzindo, conseqüentemente, a participação nas emissões brasileiras de $\mathrm{CO}_{2}$ e as emissões brasileiras como um todo.

Tal necessidade se torna mais evidente com as incertezas e indefinições relacionadas após o término do primeiro período de compromisso do Protocolo de Quioto, referente aos anos de 2008 a 2012. Há, entretanto, uma possibilidade de que as metas de redução das emissões sejam estendidas a países em desenvolvimento, como o Brasil, tornando importante a identificação de alternativas existentes para a mitigação de suas emissões.

Dada a importância do modal rodoviário de cargas para a economia brasileira, a busca de alternativas que resultem em redução de custos ou melhoria na eficiência energética geram efeitos multiplicadores positivos para a economia, seja através de aumento na competitividade dos produtos brasileiros, seja através da queda na dependência de combustíveis fósseis, respectivamente. Neste sentido, este artigo procura verificar quais são os impactos do estado de conservação das rodovias tanto nos custos de transporte quanto nas emissões de $\mathrm{CO}_{2}$. Para tanto, é avaliada a hipótese de que "rodovias em melhores estados de conservação implicam benefícios econômicos e ambientais".

O principal objetivo deste trabalho é analisar e quantificar o impacto decorrente das condições de conservação das rodovias sobre os custos privados de transporte e sobre as emissões de $\mathrm{CO}_{2}$. Especificamente, o enfoque privado buscou verificar como o estado de conservação das rodovias interfere nos custos de transporte de um motorista em particular, considerando como variáveis o consumo de combustível, o tempo de viagem e os custos de manutenção do veículo. Com relação aos impactos ambientais, foi feita uma valoração dos benefícios resultantes de uma redução das emissões de $\mathrm{CO}_{2}$ decorrentes de uma melhoria nas condições das rodovias brasileiras.

Busca-se, portanto, assim verificar se rodovias bem conservadas, de fato, resultam em menores custos de transporte (decorrentes 
da redução no consumo de combustível, no tempo de viagem e no custo de manutenção do caminhão) bem como em menores emissões de $\mathrm{CO}_{2}$ (ou seja, “poupam” energia), para que seja possível identificar alternativas de maior eficiência econômica e energética nos transportes, auxiliando nas práticas para um transporte sustentável.

A seção seguinte apresenta o referencial teórico, assim como a metodologia adotada. Na seção 4 são apresentados os principais resultados e na seção 5, as conclusões.

\subsection{Os custos de transporte}

A identificação dos determinantes dos custos do transporte rodoviário tem sido objeto de diversos estudos. Berger (1975), minimizando os custos de transporte para madeira de eucalipto, afirma que a distância é o fator mais importante no custo de transporte, mas também destaca que a qualidade das estradas, a intensidade do trânsito, a densidade da produção e o produto transportado também afetam os custos.

Correa Junior (2001) observou que os valores de frete de soja a granel praticados durante as safras de 1998 a 2000 foram influenciados por fatores como: distância percorrida, existência de praças de pedágio, sazonalidade da demanda por transporte e condições das vias utilizadas. Dentre as conclusões mais importantes, o autor observou que a elevação dos custos operacionais (como por exemplo, o preço do óleo diesel) e a implantação de novas praças de pedágio entre 1999 e 2000 podem ter desfavorecido a preferência por melhores estradas. Além disso, as condições da via parecem ser um diferencial no caso do estado de Mato Grosso.

Lima (2006) estimou os custos logísticos com combustível, em termos macroeconômicos. O autor cita que em 1996 o diesel representava $16,8 \%$ do custo total de uma carreta, aumentando a participação para $31,8 \%$ em 2004. Segundo esse mesmo estudo, cerca de $55 \%$ de todo o diesel consumido no Brasil em 2004 foram destinados ao transporte rodoviário de carga, o que equivale a 21,7 bilhões de litros e a R \$32,3 bilhões. 


\section{Material e métodos}

\subsection{Referencial Teórico}

Segundo a Teoria Econômica do Bem-estar, as "Externalidades" são consideradas uma das fontes de ineficiência de mercado, e ocorrem quando as relações de produção têm efeitos positivos ou negativos sobre o bem-estar de terceiros. Além disso, os causadores dos efeitos não pagam ou recebem nada pelas externalidades resultantes de sua atividade.

Uma característica da externalidade decorre do fato dela possuir um caráter incidental, involuntário. Ademais, a externalidade assume a característica de inevitável, ou evitável apenas quando se incorre em um certo custo social. Desta forma, mesmo o responsável pela geração da externalidade não consegue eliminá-la sem incorrer em despesas adicionais.

$\mathrm{O}$ aquecimento global é um exemplo de efeitos exportados. Enquanto os países desenvolvidos são os maiores responsáveis pelo problema, os efeitos são sentidos, principalmente, nos outros países, que precisam se adaptar às mudanças. Quando isso acontece, existe uma propensão a ignorar os efeitos dos projetos (para atividades cujos poluentes afetam apenas a vizinhança do projeto, é mais fácil identificar os custos e imputá-los ao projeto).

Sob o ponto de vista alocativo, a situação ideal seria internalizar completamente as externalidades, isto é, atribuir preço de mercado a um subproduto incidental. Entretanto, o número de externalidades passíveis de internalização é muito limitado. Poluição ou efeitos adversos no meio ambiente, de acordo com Contador (1997), são impossíveis de serem eliminados por tal procedimento.

Não existe uma metodologia perfeitamente estabelecida e aceita para quantificar as externalidades. Dados os enfoques conhecidos, deve-se buscar a solução mais adequada para o caso. Neste sentido, Contador (1997) adotou como metodologia a das "variações compensatórias", ou seja, um esquema de pagamentos entre grupos, como forma de garantir que o bem-estar coletivo não seja reduzido. Por este enfoque, as pessoas ou empresas que ficassem em melhor situação com a presença da externalidade estariam dispostas a pagar uma quantia positiva $\left(\mathrm{V}_{\mathrm{i}}\right)$ para 
evitar ficar sem o efeito externo. Já as pessoas/firmas prejudicadas pela externalidade, por outro lado, exigiriam uma quantia mínima, negativa $\left(\mathrm{V}_{\mathrm{i}}\right)$, como forma de tolerância aos efeitos externos e também para voltar ao seu nível de bem-estar inicial.

Se os efeitos externos afetam indivíduos e empresas de tal forma que a soma aritmética das variações compensatórias individuais seja positiva $\left(\sum \mathrm{V}_{\mathrm{i}}>0\right)$, então os beneficiados conseguem mais do que compensar os prejudicados pelas perdas e a externalidade é considerada positiva (deve ser computada como benefício do projeto).

Pressupondo competição perfeita, a Figura 1 traz o nível de atividade que gera poluição no eixo horizontal $(Q)$ e os custos e benefícios monetários no eixo vertical. BMLP é o benefício marginal líquido privado. O poluidor incorrerá em custos ao realizar a atividade que provocará aumento na poluição, e receberá benefícios na forma de receita. A diferença entre as receitas e os custos é o benefício privado líquido. CEM é o custo externo marginal, ou seja, o valor do dano extra causado pelo aumento da poluição decorrente da atividade, e é crescente com o nível de produto $(Q)$.

Figura 1 - Definição econômica da poluição ótima.

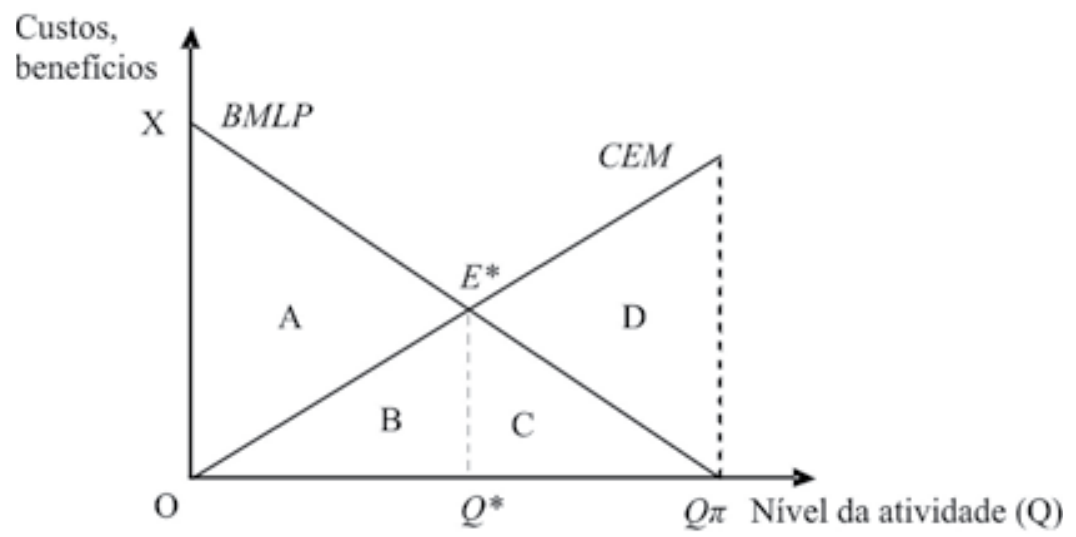

Fonte: Baseado em Pearce e Turner (1994).

O nível ótimo de externalidade encontra-se no ponto $E^{*}$, no cruzamento de BMLP com CEM. Já que ambas as curvas são marginais, as áreas 
abaixo delas correspodem às magnitudes totais, isto é, a área sob BMLP é o benefício líquido privado total do poluidor e a área sob CEM corresponde ao custo externo total. Para se obter os resultados para a sociedade, devese maximizar a diferença entre os benefícios e custos envolvidos.

O triângulo $O X E^{*}$ é a maior área dos benefícios líquidos obtidos e, conseqüentemente, $Q^{*}$ é o nível ótimo de atividade. A quantidade ótima do dano econômico correspondente ao nível ótimo de poluição $\left(Q^{*}\right)$ é dada pela área $O E^{*} Q^{*}$, correspondendo também ao nível ótimo de externalidade.

Esquematicamente, tem-se:

Área $\mathrm{A}$ = nível ótimo dos benefícios sociais

Área $\mathrm{B}=$ nível ótimo de externalidade

Área $\mathrm{A}+\mathrm{B}=$ nível ótimo dos benefícios líquidos privados do poluidor

Área $\mathrm{C}+\mathrm{D}=$ nível não-ótimo de externalidade que precisa ser removido

Área $\mathrm{C}=$ nível dos benefícios líquidos privados socialmente não justificáveis

$Q^{*}=$ nível ótimo da atividade econômica

$Q \pi=$ nível da atividade econômica que gera o máximo benefício privado.

A Figura 1 mostra que, na presença de externalidade, há uma divergência entre custos social e privado. Em $Q \pi$, o benefício privado é maximizado em $\mathrm{A}+\mathrm{B}+\mathrm{C}$, mas o custo externo é B $+\mathrm{C}+\mathrm{D}$. Então, o benefício social é $\mathrm{A}+\mathrm{B}+\mathrm{C}-\mathrm{B}-\mathrm{C}-\mathrm{D}=\mathrm{A}-\mathrm{D}$, que é menor do que $\mathrm{A}$, o benefício líquido social correspondente à $Q^{*}$.

$\mathrm{O}$ nível $\mathrm{C}+\mathrm{D}$ de externalidade é Pareto relevante, pois sua remoção leva a um ganho líquido nos benefícios sociais (Pareto superior), enquanto o nível de externalidade B é Pareto irrelevante, pois não é necessário removê-lo.

Graficamente, um programa de recuperação das rodovias equivale a aumentar a oferta, ou a disponibilidade do bem, decorrente do aumento do nível de serviço da rodovia. Conforme ilustrado na Figura 2, um projeto que aumenta a disponibilidade de um bem não precificável 
de $Q_{0}$ para $Q_{1}$, desloca a oferta perfeitamente inelástica de $S_{0}$ (sem projeto) para $S_{1}$ (com projeto). O benefício decorrente do aumento no consumo do bem (de $Q_{0}$ para $Q_{1}$ ) corresponde a um incremento no excedente do consumidor (benefício) equivalente a $Q_{0} A B Q_{1}$, a área abaixo da curva de demanda e limitada pelas quantidades com e sem o projeto.

Figura 2 - Um aumento não marginal na oferta: a mudança no excedente do consumidor ${ }^{5}$.

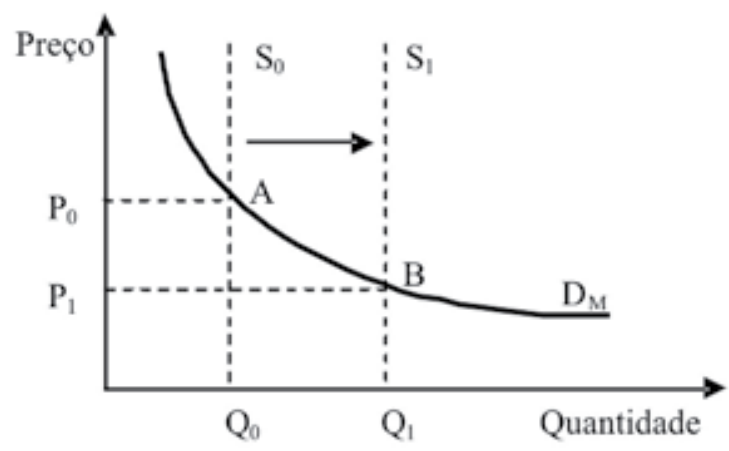

\subsection{Referencial analítico}

\subsubsection{Levantamento de dados primários}

Exceto pelo estudo de Bartholomeu (2001), não foram identificadas outras pesquisas no qual o objetivo fosse identificar o impacto do estado de conservação das rodovias nas emissões de $\mathrm{CO}_{2}$. Desta forma, o procedimento de coleta dos dados necessários, semelhante ao adotado por Bartholomeu (2001), foi a realização de ensaios de mensuração, através do acompanhamento de viagens por caminhões dotados de computadores de bordo. Ficaram sob responsabilidade da Netz Engenharia ${ }^{6}$ a instalação do computador de bordo (Blue Bird) nos caminhões, a coleta dos dados, o processo de decodificação dos resultados e o envio dos dados obtidos nas viagens realizadas.

\footnotetext{
${ }^{5}$ Análise baseada em Randall (1987).

${ }^{6}$ NETZ Engenharia. Informações disponíveis em: < http://www.netz.com.br > .
} 
O Blue Bird fornece informações sobre o desempenho da viagem (tais como velocidade média, velocidade máxima, percentual de tempo que o motorista permaneceu acima de determinada velocidade especificada, entre outros), importantes para referenciar os dados obtidos diretamente de cada viagem (tais como tempo de viagem, combustível consumido, peso da carga, entre outros).

Na pesquisa de campo foram preservadas as mesmas condições de controle em todas as viagens, ou seja, manteve-se o mesmo carregamento, o mesmo horário de viagem, as mesmas condições climáticas e os mesmos motoristas. Em todos os casos, o caminhão viajou com a carga na sua capacidade máxima, respeitando-se cada tipo de veículo/implemento.

Foram percorridas as rotas (a) Campo Grande - Santos e (b) Rondonópolis - Campo Grande. A Tabela 1 apresenta o trajeto percorrido na rota (a).

Tabela 1 - Descrição da Rota Campo Grande - Santos

\begin{tabular}{|c|c|c|c|}
\hline Principais Rodovias & Distância & Principais Cidades & Concessão \\
\hline BR-262 & $346 \mathrm{~km}$ & $\begin{array}{l}\text { Campo Grande (MS) a Três Lagoas } \\
\text { (MS) }\end{array}$ & --- \\
\hline \multirow{3}{*}{$\begin{array}{l}\text { SP-300 (Rod. } \\
\text { Marechal Rondon) }\end{array}$} & $601 \mathrm{~km}$ & $\begin{array}{l}\text { Andradina (SP) a Laranjal Paulista } \\
\qquad(\mathrm{SP})\end{array}$ & --- \\
\hline & & & \multirow{3}{*}{ Colinas } \\
\hline & & Tietê (SP) a Porto Feliz (SP) & \\
\hline SP-075 & $22 \mathrm{~km}$ & & \\
\hline $\begin{array}{l}\text { SP-280 (Rod. Pres. } \\
\text { Castelo Branco) }\end{array}$ & $60 \mathrm{~km}$ & Araçariguama (SP) a São Paulo (SP) & ViaOeste \\
\hline $\begin{array}{l}\text { SP-150 (Rod. } \\
\text { Anchieta) }\end{array}$ & $71 \mathrm{~km}$ & $\begin{array}{l}\text { S. Bernardo do Campo (SP) a Santos } \\
\text { (SP) }\end{array}$ & $\begin{array}{l}\text { Ecovias dos } \\
\text { Imigrantes }\end{array}$ \\
\hline
\end{tabular}

Fonte: Guia 4 Rodas (2004).

O trajeto percorrido entre Rondonópolis (MT) e Campo Grande (MS) (rota (b)) compreende ao trecho da BR-163 entre estas duas cidades, e não possui trechos concedidos. A Figura 3 ilustra os trajetos percorridos em cada rota. 
714 - Impactos econômicos e ambientais decorrentes do estado de conservação das rodovias brasileiras: um estudo de caso

Figura 3 - Trajeto percorrido na rota (a) Campo Grande - Santos e (b) Rondonópolis - Campo Grande.

Figura (a)

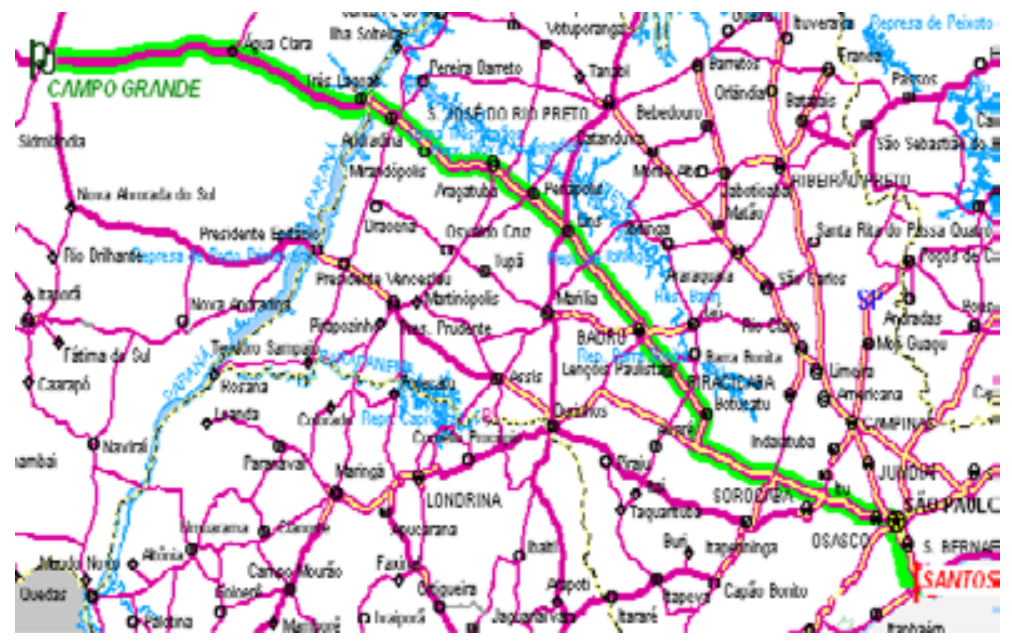

Figura (b)

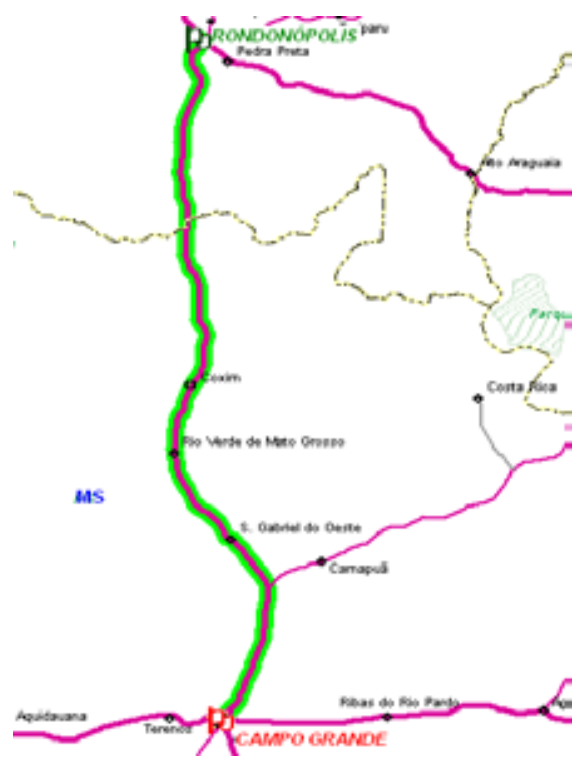

Fonte: Guia 4 Rodas (2004). 
As duas rotas estudadas foram classificadas de acordo com as condições de conservação do pavimento, tomando como base os resultados da Pesquisa Rodoviária (CNT, 2005). A Tabela 2 apresenta a classificação das rotas assim como dados relativos a pesquisa de campo.

Tabela 2 - Características das rotas estudadas e das viagens realizadas para a coleta de dados

\begin{tabular}{lcccc}
\hline Rota & Classificação & $\begin{array}{c}\mathrm{N}^{\circ} \text { de } \\
\text { veículos }\end{array}$ & $\begin{array}{c}\mathrm{N}^{\circ} \text { de viagem } \\
\text { por veículo }\end{array}$ & $\begin{array}{c}\text { No total de } \\
\text { viagens }\end{array}$ \\
\hline
\end{tabular}

a) Campo Grande -

Santos. (1.100 km)

Melhor

3

4

12

b) Rondonópolis - Campo

Grande. (480 km)

Pior $\quad 3 \quad 4$

12

Fonte: Dados da pesquisa.

A partir das viagens realizadas em cada rota, buscou-se avaliar como as condições da rodovia impactam os resultados (consumo de combustível, tempo de viagem, manutenção do veículo e emissões de $\mathrm{CO}_{2}$ ). Cada rota foi percorrida por três caminhões do modelo Scania R124-420, todos fabricados em 2004, com implemento bitrem-graneleiro, 7 eixos no conjunto e Peso Bruto Total Combinado - PBTC (peso do cavalo mais o peso do semi-reboque mais o peso da carga transportada) de $57 \mathrm{t}$.

As viagens na rota (a) foram realizadas em abril de 2005 e na rota (b), em julho do mesmo ano. Em cada viagem, além dos dados fornecidos pelo Blue Bird, também foram coletados o tempo gasto e o consumo de combustível (este foi considerado nos cálculos do benefício econômico e também foi utilizado como proxy para a quantificação das emissões).

\subsubsection{Estimativa dos parâmetros econômicos e ambientais}

Os parâmetros econômicos considerados dizem respeito ao consumo de combustível $(1 / 100 \mathrm{~km})$, ao tempo de viagem $(\mathrm{h} / 100 \mathrm{~km})$ e ao gasto com manutenção do veículo $(\mathrm{R} \$ / 100 \mathrm{~km})$ nas rotas percorridas. 
Com relação aos dois primeiros parâmetros, foi realizada uma análise estatística dos dados coletados a partir dos experimentos conduzidos. O teste de hipótese considerou a diferença entre duas médias, admitindo que as variâncias são desconhecidas, mas supostamente diferentes (Hoffmann, 1991), o que altera o número de graus de liberdade, tornando a análise mais apurada. No caso, buscou-se testar (rejeitar) a hipótese nula de que o consumo médio de combustível e o tempo médio de viagem são iguais para rotas com diferentes estados de conservação, com base em amostras aleatórias e independentes. A hipótese alternativa testada foi de que os valores médios observados nas rotas em piores estados de conservação são maiores dos obtidos em rotas melhores.

a) Consumo médio de combustível

Supõe-se que o consumo de combustível é função do estado de conservação da rodovia. Assim, o consumo do caminhão trafegando por rotas em diferentes estados de conservação deve ser estimado a partir dos dados primários levantados. Com os dados de quilometragem total percorrida e consumo total de combustível, pode-se obter o consumo médio em litros por $\mathrm{km}$.

Em cada grupo de pavimento ("Melhor", "Pior"), tomou-se a média destes valores, encontrando o consumo médio (em l/100 km) para as rotas com diferentes condições de conservação (eq. 1).

$$
\operatorname{ConsMed}_{j}=\frac{\sum_{i=1}^{n} \frac{\text { ConsumoTotal }(l)}{\text { Distância }(\mathrm{km})} \times 100}{n}
$$

no qual:

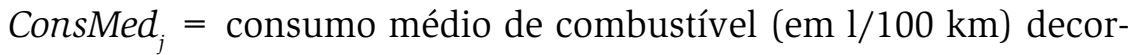
rente da utilização de rotas com determinado estado de conservação ( $j$ = condição da rodovia: "Melhor", "Pior");

Consumo Total $=$ quantidade total de combustível consumido nas viagens $(i=$ número da viagem: $1,2, \ldots, \mathrm{n} ; j=$ condição da rodovia: "Melhor", "Pior");

Distância $=$ quilometragem total percorrida durante as viagens $(i=$ número da viagem: $1,2, \ldots, \mathrm{n} ; j$ = condição da rodovia: "Melhor", "Pior"); 
b) Tempo médio de viagem

Estradas em melhores condições de infra-estrutura devem permitir uma maior velocidade média de viagem, resultando numa redução no tempo de viagem. Assim, da mesma forma, o tempo de viagem é função dos diferentes estados de conservação, e deve ser estimado a partir dos dados primários levantados. Com os dados de quilometragem total percorrida e do tempo total da viagem, pode-se obter o tempo médio (h/100 km).

Em cada grupo de pavimento ("Melhor”, “Pior”), tomou-se a média destes valores, encontrando o tempo médio (em h/100 km) para as rotas com diferentes condições de conservação (eq. 2).

$$
\text { TempoMed }_{j}=\frac{\sum_{i=1}^{n} \frac{\text { TempoTotal }(h)}{\text { Distância }(\mathrm{km})} \times 100}{n}
$$

no qual:

TempoMed $_{j}=$ tempo médio necessário decorrente da utilização de rotas com determinado estado de conservação, em h/100 km ( $j=$ condição da rodovia: "Melhor", "Pior");

Tempo Total $=$ tempo total gasto nas viagens $(i=$ número da viagem: $1,2, \ldots, \mathrm{n} ; j$ = condição da rodovia: "Melhor", "Pior");

Distância $=$ quilometragem total percorrida durante as viagens $(i$ = número da viagem: $1,2, \ldots, \mathrm{n} ; j$ = condição da rodovia: "Melhor", "Pior");

De acordo com Reis (2006), estradas em mau estado reduzem a velocidade dos veículos, conseqüentemente, o motorista consegue realizar um número inferior de viagens em relação ao potencial, aumentando o custo fixo por viagem (depreciação, remuneração do capital, seguros e licenciamento, entre outros).

Portanto, quando se considera o tempo na análise, há também um impacto indireto nos custos fixos de uma viagem, que são expressos em $\mathrm{R} \$ / \mathrm{h}$. Quanto mais tempo o caminhão estiver em movimento, mais os custos fixos se diluem nas viagens. Assim, o interessante é aumentar número de viagens ou a distância percorrida num mesmo espaço de tempo.

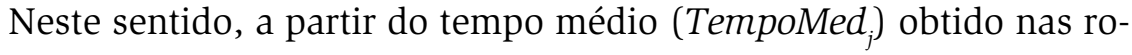
tas com diferentes estados de conservação, o "custo indireto de tempo" 
Impactos econômicos e ambientais decorrentes do estado de conservação das rodovias brasileiras: um estudo de caso

será estimado a partir de custos fixos estimados pelo Grupo de Pesquisa e Extensão em Logística Agroindustrial (Esalq-LOG,) tomando como base metodologia desenvolvida por Figueiredo et al. (2003).

c) Gasto com manutenção do veículo

Também supõe-se que o custo de manutenção do veículo seja função direta do estado de conservação das rodovias. Segundo Reis (2006, p.1), “o custo operacional de veículos, especialmente dos caminhões, é fortemente afetado pelo estado de conservação do pavimento das rodovias". No caso dos custos variáveis (tais como combustível, pneus, peças, lubrificação e lavagem), os custos aumentam consideravelmente à medida em que o estado de conservação da rodovia piora. No caso dos custos fixos, estes foram considerados quando analisados o tempo de viagem, na seção anterior.

Assim sendo, os custos de manutenção do veículo foram calculados a partir de dados secundários com base em estudo realizado por Reis (2006), cujo o objetivo foi verificar o impacto das condições da rodovia nos custos de manutenção de uma Scania $4 \times 2$ tracionando uma carreta de 3 eixos, uma vez que este veículo apresentou, segundo estudo tomado como referência pelo autor (Bodeli, 1997), uma menor sensibilidade, evitando uma superestimação dos resultados. Para Reis (2006), uma rodovia "deficiente" aumenta em 18,7\% os custos de manutenção do veículo em relação a uma estrada "boa”, percentual adotado no cálculo da presente pesquisa.

\section{d) Emissões de $\mathrm{CO}_{2}$}

As variáveis ambientais referem-se às emissões de $\mathrm{CO}_{2}$ decorrentes do percurso de rodovias em diferentes estados de conservação.

Constatou-se um número significativo de artigos internacionais que buscavam quantificar as emissões de poluentes globais e, principalmente, locais. Nenhum dos artigos considerou, especificamente, as condições das rodovias como determinantes das emissões pelo transporte. Em geral, as metodologias adotadas foram basicamente a aplicação de softwares específicos para os cálculos das emissões, de acordo com os objetivos a que se propunham alcançar. Uma desvantagem decorrente da utilização destes programas está relacionada aos valores default 
sugeridos por eles, normalmente baseados em estimativas para as frotas norte-americanas e européias e, portanto, não refletindo adequadamente a realidade brasileira.

Diante disso, optou-se por adotar uma metodologia elaborada a partir das propostas e valores obtidos das seguintes fontes: IPCC (1997), Bartholomeu (2001) e Brasil (2002a). A principal finalidade desta metodologia é fornecer uma seqüência de procedimentos de cálculo para as estimativas das emissões por veículos rodoviários de carga, considerando os efeitos das condições das rodovias sobre o consumo de combustível.

Assim como foi assumido em Brasil (2002b), as estimativas dos GEE emitidos pelo transporte rodoviário pesado também se restringiram às emissões da combustão de óleo diesel, uma vez que o transporte de cargas é predominantemente movido a diesel. Além disso, foi adotada a premissa de que a combustão é completa, isto é, todo o carbono do combustível é convertido em $\mathrm{CO}_{2}$ (foram desconsiderados $\mathrm{CO}$ e NMVOC, que são posteriormente transformados em $\mathrm{CO}_{2}$ na atmosfera). Foram desconsideradas também as emissões referentes ao $\mathrm{N}_{2} \mathrm{O}$ e $\mathrm{CH}_{4}$, tal como adotado por Álvares e Linke (2003) e sugerido pelo GHG Protocol (2005).

De acordo com Branco et al. (2003), os fatores de emissão dos veículos dependem das características do tráfego local, tais como o volume, a velocidade média, a inclinação da pista, do número de faixas de rolamento, tipos de veículos e classes de peso e indicativos do nível de serviço da pista. Além disso, os fatores de emissão de veículos também dependem da idade e tecnologia do veículo, assim como das condições de manutenção e operação (carga, velocidade e modo de conduzir).

Foi adotado o fator de emissão de $\mathrm{CO}_{2}$ a partir do diesel de $2,75 \mathrm{~kg} / \mathrm{l}$, valor médio entre os sugerido por Brasil (2002b) e Bartholomeu (2001). Entretanto, este valor não considera as especificações levantadas por Branco et al. (2003), mas corresponde a uma estimativa geral que considera as características médias do diesel comercializado no Brasil.

Portanto, para calcular as emissões de $\mathrm{CO}_{2}$ pelos caminhões trafegando em estradas com diferentes condições de conservação, foi utilizada a eq. (3). 


$$
E_{j}=\frac{\text { CEMed }_{j} \times E}{100}
$$

no qual:

$E_{j}=$ emissão média de $\mathrm{CO}_{2}$ pelos caminhões trafegando em estradas com diferentes condições de conservação $(j=$ condição da rodovia: "Melhor", "Pior"), em kg CO$/$ t.100 km;

CEMed $_{j}=$ consumo específico médio dos caminhões para cada grupo de pavimento ( $j$ = condição da rodovia: "Melhor", "Pior"), em l/t.100km;

$F E=$ fator de emissão de $\mathrm{CO}_{2}$ pelo diesel, cujo valor adotado é 2,75 $\mathrm{kg} / \mathrm{l}$.

O consumo específico anula o possível efeito da variabilidade do peso da carga transportada, e indica a quantidade de litros consumida por tonelada transportada a cada 100 quilômetros, conforme a eq. (4).

$$
C E=\frac{C C}{P \times D \times 100}
$$

no qual:

$C E=$ Consumo específico de combustível $(1 / \mathrm{t} .100 \mathrm{~km})$;

$C C=$ Consumo de combustível (l);

$P=$ Peso Bruto Total Combinado (t); e

$D=$ Distância percorrida $(\mathrm{km})$.

O consumo específico médio corresponde à média simples dos consumos específicos encontrados em cada viagem, separados por grupos de condições de conservação da pista. Deste modo, a diferença das emissões pelos caminhões será observada através do consumo de combustível, multiplicado pelo fator de emissão.

De maneira simplificada, o valor encontrado para $E_{j}$ corresponde a um “índice de emissão" por veículos rodoviários pesados de acordo com a condição da rodovia; assim sendo, reflete a quantidade de $\mathrm{CO}_{2}$ emitida (em kg) para transportar 1 tonelada a cada 100 quilômetros, para os diferentes estados de conservação considerados na pesquisa. Conhecendo a carga total transportada e a distância percorrida, é possível estimar a emissão 
resultante de uma determinada viagem. No agregado, é possível calcular as emissões de uma transportadora, ou até mesmo de um setor econômico.

\subsubsection{Valoração dos benefícios econômicos e ambientais}

Dado que uma melhor condição de pavimentação deve implicar menores valores de consumo médio de combustível, tempo médio de viagem, gasto com manutenção do veículo e emissões de $\mathrm{CO}_{2}$, há um benefício (econômico e ambiental) implícito resultante de viagens em rodovias em boas condições de conservação em relação às viagens realizadas em rodovias com condições precárias.

A análise é feita considerando a economia obtida a cada 100 quilômetros percorridos, independentemente se o motorista é autônomo ou contratado por uma empresa transportadora (assumiu-se que, em ambos os casos, os benefícios observados seriam os mesmos). A análise também refere-se ao curto-prazo, no qual os benefícios ainda não foram percebidos pela sociedade.

a) Benefício com consumo de combustível

O benefício com consumo de combustível $(B C)$ que o motorista observa é obtido a partir da subtração do consumo médio em rodovias em bom estado do consumo médio em rodovias em mau estado. Assim, o valor do benefício para o motorista $(V B c)$ é calculado como:

$$
V B c=B c \times P
$$

no qual:

$V B c=$ valor do benefício (economia) com consumo de combustível resultante do percurso em rodovias com melhor infra-estrutura $(\mathrm{R} \$ / 100 \mathrm{~km})$;

$B c=$ benefício resultante de uma redução/economia no consumo médio de combustível $(1 / 100 \mathrm{~km})$; e

$P=$ preço médio do diesel em maio de 2006, cujo valor médio nacional foi de $\mathrm{R} \$ 1,915^{7}$.

\footnotetext{
${ }^{7}$ Fonte: Agência Nacional do Petróleo (ANP). Disponível em: http://www.anp.gov.br/ doc/petroleo/ relatorios_precos/2006/Diesel_2006.pdf. Acesso em: 21 julho de 2006.
} 
b) Benefício com tempo de viagem

O benefício privado resultante de uma redução no tempo de viagem (Bt) dada uma melhoria na condição de pavimentação da rodovia é dado pela subtração dos valores obtidos (tempo médio em rodovias em mau estado - tempo médio em rodovias em bom estado).

Uma melhoria nas estradas deve possibilitar um aumento na velocidade média, favorecendo um aumento no número de viagens realizadas ou na distância percorrida por dia.

Para valorar o benefício privado $(V B t)$, foram considerados os benefícios diretos, resultantes de uma maior remuneração relativa para o motorista e os benefícios indiretos, resultantes de uma diluição dos custos fixos de transporte. $\mathrm{O}$ valor do benefício direto $\left(V B t_{d}\right)$ foi calculado a partir da eq. (6).

$$
V B t_{d}=B t \times M
$$

no qual:

$V B t_{d}=$ valor do benefício direto (economia) com tempo de viagem resultante do percurso em rodovias com melhor infra-estrutura (R $\$ / 100$ $\mathrm{km})$; e

$B t$ = benefício resultante de uma redução/economia no tempo médio de viagem $(\mathrm{h} / 100 \mathrm{~km})$; e

$M=$ valor da hora paga ao motorista.

O valor da hora paga ao motorista adotado foi de $\mathrm{R} \$ 7,52$, obtido considerando o piso salarial para carreteiros da região metropolitana do estado do Rio Grande do Sul, de R \$83,00, mais 22 diárias de R\$ 20,00 relativas à alimentação, totalizando $\mathrm{R} \$ 1.323,00 /$ mês (Setsergs, 2006). Foi suposto que o motorista trabalha 8 horas por dia, durante 22 dias.

O valor do benefício indireto $\left(V B t_{i}\right)$ foi calculado a partir da eq. (7).

$$
V B t_{i}=B t \times C F
$$

no qual: 
$V B t_{i}=$ valor do benefício indireto (economia) com tempo de viagem resultante do percurso em rodovias com melhor infra-estrutura $(\mathrm{R} \$ / 100 \mathrm{~km})$; e

$B t=$ benefício resultante de uma redução/economia no tempo médio de viagem $(\mathrm{h} / 100 \mathrm{~km})$; e

$C F=$ custos fixos estimados pelo Esalq-LOG em julho de 2006 $(\mathrm{R} \$ / \mathrm{h})$ para bitrem $(\mathrm{R} \$ 32,64 / \mathrm{h})$.

Portanto, o VBt pode ser expresso pela eq. (8).

$V B t=V B t_{d}+V B t_{i}$

no qual:

$V B t=$ valor do benefício (economia) com tempo de viagem resultante do percurso em rodovias com melhor infra-estrutura (R \$/100 $\mathrm{km})$;

$V B t_{d}=$ valor do benefício direto (economia) com tempo de viagem resultante do percurso em rodovias com melhor infra-estrutura (R $\$ / 100$ $\mathrm{km})$; e

$V B t_{i}=$ valor do benefício indireto (economia) com tempo de viagem resultante do percurso em rodovias com melhor infra-estrutura $(\mathrm{R} \$ / 100 \mathrm{~km})$.

ou pela eq. (9).

$V B t=B t(M+C F)$

no qual:

$V B t=$ valor do benefício (economia) com tempo de viagem resultante do percurso em rodovias com melhor infra-estrutura (R \$/100 $\mathrm{km})$;

$B t$ = benefício resultante de uma redução/economia no tempo médio de viagem $(\mathrm{h} / 100 \mathrm{~km})$;

$M=$ valor da hora paga ao motorista; e

$C F=$ custos fixos de transporte.

c) Benefício com gasto de manutenção do veículo

Dado que o gasto anual com a manutenção do caminhão é equivalente à distância total percorrida numa viagem multiplicada pelo custo 
Impactos econômicos e ambientais decorrentes do estado de conservação das rodovias brasileiras: um estudo de caso

médio de manutenção do veículo, o valor do benefício $(\mathrm{VBm})$ é obtido diretamente através da diferença entre o gasto médio de manutenção em rodovias em mau estado e o gasto médio de manutenção em rodovias em bom estado.

$$
V B m=B m \times C V M e
$$

no qual:

$V B m=$ valor do benefício (economia) com manutenção do veículo resultante do percurso em rodovias com melhor infra-estrutura ( $\mathrm{R} \$ / 100$ $\mathrm{km})$;

$B m$ = benefício resultante de uma redução/economia no custo médio de manutenção do caminhão (\%); e

CVMe $=$ custos variáveis estimados pelo Esalq-LOG em julho de $2006(\mathrm{R} \$ / \mathrm{km})$ para bitrem $(\mathrm{R} \$ 1,75 / \mathrm{km})$.

O benefício $(\mathrm{Bm})$ refere-se aos valores encontrados por Reis (2006), em termos percentuais.

d) Benefício econômico total

O valor do Benefício Econômico Total (VBET) para o motorista é dado pela soma dos benefícios econômicos calculados anteriormente (eq. 11).

$$
V B E T=V B c+V B t+V B m
$$

no qual:

$V B c=$ valor do benefício (economia) com consumo de combustível resultante de uma viagem em rodovias com melhor infra-estrutura (R\$/ viagem);

$V B t=$ valor do benefício (economia) com tempo de viagem resultante de uma viagem em rodovias com melhor infra-estrutura (R\$/ viagem);

$\mathrm{VBm}$ = valor do benefício (economia) com manutenção do veículo resultante de uma viagem em rodovias com melhor infra-estrutura (R \$/ viagem); 
e) Benefícios ambientais - redução das externalidades negativas referentes às emissões. O benefício ambiental $(B e)$, decorrente de uma redução nas emissões caso se observasse uma melhoria nas condições das rodovias, é considerado uma redução na externalidade negativa (nível das emissões) originado de um investimento em recuperação das rodovias. O Be deve ser estimado por meio da subtração dos valores obtidos (emissão média de $\mathrm{CO}_{2}$ em rodovias em mau estado - emissão média de $\mathrm{CO}_{2}$ em rodovias em bom estado).

Para a valoração deste benefício $(\mathrm{VBe})$, optou-se por considerar o preço médio da tonelada de carbono que vem sendo adotado como referência atual nos cálculos gerais para projetos de MDL no escopo do Protocolo de Quioto ${ }^{8}$, de US\$ 10,00/t CO e. Neste mercado, entretanto, verifica-se certa variação nos preços da tonelada de carbono negociados, em função de alguns fatores. Um deles corresponde ao tipo de negociação bilateral entre as partes envolvidas e, conseqüentemente, do valor acordado entre elas. Além disso, o preço do carbono também depende do status do projeto. Projetos de MDL em fases mais adiantadas no ciclo de aprovação e, principalmente, com créditos de carbono obtidos, certamente obterão maiores preços para a tonelada de $\mathrm{CO}_{2}$ equivalente, uma vez que os riscos envolvidos se reduzem.

O VBe é calculado a partir da eq. (12).

$V B e=B e \times R C E x T C$

no qual:

$V B e=$ valor do benefício (externalidade) com emissão de $\mathrm{CO}_{2}$ resultante de uma viagem em rodovias com melhor infra-estrutura (R \$ t.100 km);

$B e=$ benefício resultante de uma redução nas emissões médias de $\mathrm{CO}_{2}(\mathrm{~kg} \mathrm{CO} / \mathrm{t} .100 \mathrm{~km})$;

$R C E=$ preço da tonelada de $\mathrm{CO}_{2} \mathrm{e}(\mathrm{US} \$ / \mathrm{t}) ; \mathrm{e}$

$T C=$ taxa de câmbio (R\$2,30/US\$ 1,00).

\footnotetext{
${ }^{8}$ Há outros mercados e bolsas que negociam carbono, tais como o mercado europeu, a European Union's Emissions Trading Schene (EU ETS) e a Bolsa de Chicago, a Chicago Climate Exchange (CCX), no qual estão sendo praticados preços próximos de US\$ 18,00/tonelada e US\$ 3,50/t, respectivamente (Müller, 2006).
} 
Da mesma forma que na valoração dos benefícios econômicos, optou-se por considerar a análise pela ótica dos benefícios ambientais sem discriminar o agente (autônomo ou transportadora).

Rigorosamente, entretanto, o VBe não deve refletir fielmente as reduções nas externalidades negativas, uma vez que, ao adotar o preço da tonelada de carbono no escopo do PQ, os outros benefícios indiretos para a humanidade não estão sendo considerados. Assim, na valoração das externalidades deveriam também ser adicionados os benefícios indiretos para o meio ambiente local e global, para a comunidade diretamente envolvida (próxima às rodovias) e para a sociedade como um todo, devido à contribuição para a mitigação das emissões de GEE e, conseqüentemente, aos seus impactos negativos sobre o aquecimento global.

Porém, ainda há um desconhecimento, por parte da comunidade científica, a respeito da dimensão dos impactos e de seus valores monetários, dificultando a obtenção de um valor mais próximo da externalidade. Dessa forma, a valoração da redução nas externalidades negativas relacionadas às reduções de emissão no transporte deve ser considerada como bastante conservadora neste estudo.

\section{Resultados}

Na Tabela 3 são apresentados os dados qualitativos resultantes do percurso das duas rotas (velocidades médias e a autonomia dos veículos em cada viagem).

\subsection{Cálculo dos benefícios econômicos e respectivas valorações}

a) Benefício com consumo de combustível

Foi observada uma diferença no consumo médio de combustível entre as rotas com diferentes condições de conservação do pavimento. A Tabela 4 fornece uma análise qualitativa dos dados coletados, os quais apresentaram comportamento consistente, refletido pela baixa dispersão em relação à média, resultando numa pequena variância e desvio-padrão. Os dados com maior freqüência são representados pela moda. 
Tabela 3 - Resultados das medições realizadas para as duas rotas estudadas

\begin{tabular}{ccccc}
\hline \multirow{2}{*}{ Veículo } & (a) Campo Grande - Santos & (b) Rondonópolis - Campo Grande \\
& \multicolumn{2}{c}{ (Melhor) } & & (Pior) \\
\cline { 2 - 5 } & Vmed & $k m / l$ & Vmed & $\mathrm{km} / \mathrm{l}$ \\
\hline 1 & 67 & 1,94 & 64 & 1,78 \\
1 & 68 & 1,78 & 66 & 1,65 \\
1 & 69 & 1,85 & 69 & 1,68 \\
1 & 68 & 1,91 & 69 & 1,73 \\
2 & 67 & 1,79 & 70 & 1,58 \\
2 & 68 & 1,89 & 71 & 1,61 \\
2 & 71 & 1,74 & 66 & 1,80 \\
2 & 70 & 1,86 & 65 & 1,81 \\
3 & 73 & 1,64 & 63 & 1,82 \\
3 & 66 & 1,87 & 67 & 1,58 \\
3 & 69 & 1,86 & 69 & 1,55 \\
3 & 72 & 1,79 & 69 & 1,77 \\
\hline
\end{tabular}

Fonte: Resultados da pesquisa, baseados em dados fornecidos pela Netz Engenharia.

Tabela 4 - Análise estatística dos dados de consumo de combustível coletados $(1 / 100 \mathrm{~km})$

\begin{tabular}{lccc}
\hline Rota & Média & Desvio-padrão & Moda \\
\hline (a) Campo Grande - Santos (Melhor) & 54,85 & 2,59 & 53,76 e 55,86 \\
(b) Rondonópolis - Campo Grande (Pior) & 59,13 & 3,54 & 63,29 \\
\hline
\end{tabular}

Fonte: Resultados da pesquisa.

O desempenho verificado pelos veículos apresentou diferença quando percorridas rotas com condições de conservação distintas: a rota (a) foi a mais eficiente, resultando num consumo médio de 0,5485 l/km, o que equivale a uma economia de $7,8 \%$ no consumo de combustível quando passou da rota Pior para a Melhor.

No caso do teste de hipótese aplicado, o desempenho obtido pelo caminhão Scania foi estatisticamente significativo ao nível de significância de $5 \%$, indicando que deve-se rejeitar a hipótese de que o consumo médio de combustível é o mesmo para rotas em diferentes estados de conservação. 
A Tabela 5 apresenta os benefícios resultantes da utilização da melhor opção. Para o cálculo do Valor do Benefício $(V B c)$ foi considerado um preço médio para óleo diesel de $\mathrm{R} \$ 1,915 / \mathrm{I}^{9}$.

Tabela 5 - Benefícios no consumo médio de combustível decorrentes de rotas com diferentes condições de conservação, em l/100km e em R $\$ / 100$ km

\begin{tabular}{lcc}
\hline Rota & Benefício $(\mathrm{l} / 100 \mathrm{~km})$ & Valor do Benefício $(V B c)$, em $\mathrm{R} \$ / 100 \mathrm{~km}$ \\
\hline Melhor/Pior & 4,28 & 8,19 \\
\hline
\end{tabular}

Fonte: Resultados da pesquisa.

Como o benefício observado foi sempre positivo, há uma indicação de que rotas melhores consomem menos combustível do que as rotas em pior estado de conservação.

b) Benefício com tempo de viagem

Os resultados relacionados ao tempo de viagem também apresentaram consistência, como pode ser visualizado na Tabela 6 .

Tabela 6 - Análise estatística dos dados de tempo de viagem coletados (h/100 km)

\begin{tabular}{lccc}
\hline Rota & Média & Desvio-padrão & Moda \\
\hline (a) Campo Grande - Santos (Melhor) & 1,45 & 0,04 & 1,47 \\
(b) Rondonópolis - Campo Grande (Pior) & 1,49 & 0,06 & 1,45 \\
\hline
\end{tabular}

Fonte: Resultados da pesquisa.

Com relação ao tempo de viagem, também observa-se uma diferença nos resultados obtidos quando comparadas às duas rotas com diferentes estados de conservação. Apesar de menos expressiva do que a economia observada no caso do consumo de combustível, a rota $\mathrm{Me}$ lhor poupou 2,5\% do tempo quando percorrida pelo caminhão Scania.

Os dados indicaram, entretanto, que a hipótese nula não deve ser rejeitada, já que não é estatisticamente significativa ao nível de significância de $5 \%$. O parâmetro tempo de viagem pode sofrer influência

${ }^{9}$ Preço médio referente ao mês de maio de 2006 (ANP, 2006). 
de outras variáveis exógenas, mais representativas do que a própria condição da rodovia

Considerando a remuneração do motorista e os custos fixos de transporte, respectivamente $\mathrm{R} \$ 7,52 / \mathrm{h}^{10}$ e $\mathrm{R} \$ 32,64 / \mathrm{h}^{11}$, obteve-se os resultados apresentados na Tabela 7 .

Tabela 7 - Benefícios no tempo médio de viagem, em h/100 km e em R $\$ / 100$ $\mathrm{km}$

\begin{tabular}{lcccc}
\hline \multirow{2}{*}{ Rota } & Benefício & Valor do Benefício & Valor do Benefício & Valor do Benefício \\
& $(\mathrm{h} / 100 \mathrm{~km})$ & Direto $\left(V B t_{d}\right)$, em & Indireto $\left(V B t_{i}\right)$, em & $(V B t)$, em $\mathrm{R} \$ / 100$ \\
& $\mathrm{R} \$ / 100 \mathrm{~km}$ & $\mathrm{R} \$ / 100 \mathrm{~km}$ & $\mathrm{~km}$ \\
\hline Melhor $/$ Pior & 0,04 & 0,27 & 1,19 & 1,47 \\
\hline
\end{tabular}

Fonte: Resultados da pesquisa.

Com o tempo médio verificado na rota Melhor, para percorrer 1.100 km, por exemplo, são necessárias 16 horas; da mesma forma, são gastas 16h22min para percorrer a rota Pior, com a mesma extensão. Com isso, o motorista "ganharia" 1 viagem a cada 45 que fizesse apenas na rota com as condições de conservação melhor.

c) Benefício com custo de manutenção do caminhão

O cálculo do benefício resultante de uma redução no gasto de manutenção do veículo foi obtido a partir do estudo de Reis (2006), conforme descrito, e considerando como custo variável de um bitrem ${ }^{12}: \mathrm{R} \$ 1,75 / \mathrm{km}$.

Assim, o VBm será $\mathrm{R} \$ 32,67 / 100 \mathrm{~km}$ quando comparada a rota melhor com a pior.

d) Benefício total

A Tabela 8 sumariza os benefícios econômicos resultantes da utilização de rotas com diferentes estados de manutenção.

\footnotetext{
${ }^{10}$ Setsergs (2006)

${ }^{11}$ Dados calculados pelo Esalq-LOG utilizando metodologia de Figueiredo et al. (2003), referentes a julho de 2006.

${ }^{12}$ Estimativa realizada pela Esalq-LOG, referente a julho de 2006.
} 
Impactos econômicos e ambientais decorrentes do estado de conservação das rodovias brasileiras: um estudo de caso

Tabela 8 - Valores dos Benefícios Econômicos parciais e total $(\mathrm{R} \$ / 100 \mathrm{~km})$ decorrentes de rotas com diferentes condições de conservação

\begin{tabular}{lcccc}
\hline Rota & $\begin{array}{c}\text { Valor do Bene- } \\
\text { fício com Com- } \\
\text { bustível }(V B c)\end{array}$ & $\begin{array}{c}\text { Valor do Be- } \\
\text { nefício com } \\
\text { Tempo }(V B t)\end{array}$ & $\begin{array}{c}\text { Valor do Benefício } \\
\text { com Manutenção } \\
\text { do veículo }(V B m)\end{array}$ & $\begin{array}{c}\text { Valor do Benefício } \\
\text { Econômico Total } \\
(V B E T)\end{array}$ \\
\hline Melhor/Pior & 8,19 & 0,48 & 32,67 & 41,34 \\
\hline
\end{tabular}

Fonte: Resultados da pesquisa.

Portanto, os resultados indicam que rotas com condições de conservação diferentes implicam resultados econômicos bastante distintos quando percorridas pelo caminhão utilizado no experimento.

Além disso, quando tomado como base o estudo de Reis (2006), a condição precária da pista produz impacto significativamente maior sobre os custos de manutenção do caminhão que as demais variáveis consideradas isoladamente.

Supondo o caso do transporte de soja a granel de Campo Grande (MS) e de Itumbiara (GO) para o porto de Paranaguá (PR), com extensão de $1.100 \mathrm{~km}$, os benefícios econômicos decorrentes de uma rota em melhor condição de conservação resultariam numa redução de $16 \%$ no valor do frete da soja transportada pelo caminhão Scania.

\subsection{Cálculo dos benefícios ambientais e respectivas valorações (exter- nalidades)}

A Tabela 9 apresenta o consumo específico de combustível (em kg $\mathrm{CO}_{2} / \mathrm{t} .100 \mathrm{~km}$ ) e o índice de emissão (em $\mathrm{kg} \mathrm{CO} / \mathrm{t} .100 \mathrm{~km}$ ) para rotas em diferentes estados de conservação. Este valor permite à transportadora ou ao motorista estimar suas emissões totais de uma determinada viagem conhecendo apenas as condições da via (se boas ou ruins), a distância percorrida e a carga transportada.

Dado que a rota (a) apresentou menor consumo de combustível, resultará em menor nível de emissão de $\mathrm{CO}_{2}$ para transportar 1 t a cada 100 quilômetros, indicando que rotas melhores também resultam em benefícios ambientais, visto que tendem a reduzir as emissões de $\mathrm{CO}_{2}$. 
Tabela 9 - Valores médios de consumo específico de combustível e de emissão de $\mathrm{CO}_{2}$

\begin{tabular}{lcc}
\hline \multicolumn{1}{c}{ Rota } & $\begin{array}{c}\text { Consumo específico médio } \\
\text { de combustível }(\mathrm{l} / \mathrm{t} .100 \mathrm{~km})\end{array}$ & $\begin{array}{c}\text { Emissão de } \mathrm{CO}_{2}(\mathrm{~kg} \\
\left.\mathrm{CO}_{2} / \mathrm{t} .100 \mathrm{~km}\right)\end{array}$ \\
\hline $\begin{array}{l}\text { (a) Campo Grande - Santos } \\
\text { (Melhor) }\end{array}$ & 0,962 & 2,646 \\
$\begin{array}{l}\text { (b) Rondonópolis - Campo } \\
\text { Grande (Pior) }\end{array}$ & 1,037 & 2,853 \\
\hline
\end{tabular}

Fonte: Resultados da pesquisa.

A Tabela 10 apresenta os valores dos benefícios decorrentes de uma redução nas emissões para o caso estudado, em que o PBTC foi de $57 \mathrm{t}$ e a taxa de câmbio considerada foi de R\$2,30/US\$1,00.

Tabela 10 - Benefícios nas emissões de $\mathrm{CO}_{2}$, em $\mathrm{kg} \mathrm{CO}_{2} / \mathrm{t}$.km e em $\mathrm{R} \$ / 100$ $\mathrm{km}$

\begin{tabular}{lcc}
\hline Rota & $\begin{array}{c}\text { Benefício ambiental } \\
\left(\mathrm{kg} \mathrm{CO}_{2} / \mathrm{t} .100 \mathrm{~km}\right)\end{array}$ & $\begin{array}{c}\text { Valor do Benefício }(\mathrm{VBe}), \\
\text { em R } \$ / 100 \mathrm{~km}\end{array}$ \\
\hline Melhor/Pior & 0,2064 & 0,27 \\
\hline
\end{tabular}

Fonte: Resultados da pesquisa.

Quando as condições de pavimentação da pista (b) se tornam equivalentes às da pista (a), cada tonelada transportada a cada 100 quilômetros resulta num nível de emissão de 206,42 gCO $_{2}$ menor, conforme o tipo de veículo considerado.

Extrapolando os resultados obtidos nos casos deste experimento e supondo ainda que $60 \%$ das viagens realizadas em 2004 podem ser incluídas como potenciais para receberem melhorias na infra-estrutura, ter-se-ia um benefício ambiental de aproximadamente $\mathrm{R} \$ 13,8$ milhões por ano, o que equivale a cerca de $0,12 \%$ do volume necessário para recuperar toda a malha rodoviária nacional, respectivamente.

\subsection{Análise de Sensibilidade}

Apesar de os benefícios econômicos e ambientais terem sido expressos em termos de unidades dos parâmetros analisados para cada 
100 quilômetros percorridos (evitando, dessa forma, suposições), na valoração dos benefícios econômicos e ambientais (VBT), foi necessário adotar algumas considerações a respeito de determinados valores envolvidos nos cálculos, tais como: preço do diesel, remuneração do motorista, custos fixos e variáveis, preço da tonelada de carbono, taxa de câmbio, entre outros.

Esta seção procura verificar como possíveis alterações nos valores de alguns dos parâmetros mais importantes poderiam estar influenciando nos resultados.

Nesta análise de sensibilidade foi suposto que os custos e, conseqüentemente, os benefícios são lineares, ou seja, variam proporcionalmente com a distância percorrida (não há a chamada "economia de escala”). Assim, se foi verificado que o benefício com consumo de combustível no experimento agregado foi de $\mathrm{R} \$ 4,81$ a cada $100 \mathrm{~km}$ percorridos, se a rota tiver uma extensão de 1.000 ou $2.000 \mathrm{~km}$, por exemplo, os benefícios considerados não devem sofrer alterações, isto é, o valor do benefício com consumo de combustível deve ser de R\$ 48,13 e de R\$96,25, para cada caso, respectivamente.

Os benefícios econômicos relacionados à redução nos custos de manutenção do veículo representaram 76,7\% dos benefícios totais obtidos pelo Scania percorrendo uma rota em melhores condições de conservação. O consumo de combustível representou 19,2\%, o tempo de viagem respondeu por 3,4\% e as emissões contribuíram com 0,63\% dos benefícios totais, expressos em $\mathrm{R} \$ / 100 \mathrm{~km}$.

O VBT alterou-se com as variações nos valores dos parâmetros (coeteris parebus). Foram impostas variações positivas de $10 \%$ sobre os valores iniciais dos seguintes parâmetros: preço do diesel, remuneração do motorista, custos fixos e variáveis de transporte. O maior impacto sobre o VBT, dentre estes parâmetros, foi decorrente da variação nos custos variáveis de transporte, ou seja, um aumento de $10 \%$ no valor provoca uma elevação entre $7,7 \%$ no VBT. No caso de um aumento de $10 \%$ no preço do diesel, o VBT teria um acréscimo de 1,9\%. A remuneração do motorista quase não alterou o $V B T$.

A simulação para a condição da rodovia também buscou comparar o impacto, no VBT, de uma melhoria de uma rota considerada "ruim" para um estado de conservação classificado como "bom”. A redução 
dos custos variáveis estimada por Reis (2006), de 39,11\%, implicaria um aumento de $84 \%$ no VBT.

Com relação aos impactos dos benefícios ambientais sobre o VBT, verificou-se que este poderia aumentar pelo menos $2,7 \%$ e $7,6 \%$, caso os preços da tonelada de carbono fossem 40,00/t e 100,00/t, respectivamente.

\section{Conclusões}

Os resultados obtidos confirmam a hipótese de que rotas com diferentes condições de infra-estrutura resultam em custos de viagem distintos, relacionados ao consumo de combustível, ao tempo de viagem e ao gasto com manutenção do combustível. Portanto, rotas em melhores condições de conservação resultam em maiores benefícios tanto econômicos quanto ambientais.

Nas viagens realizadas foram identificadas reduções no consumo de combustível, no tempo de viagem e, especialmente, nos gastos com a manutenção dos veículos. Os resultados também apontam para uma melhoria na eficiência energética observada durante as viagens quando a opção foi a utilização das rotas com melhores condições de pavimentação. Este fato resultou em índices de emissões diferentes para as viagens realizadas.

No que diz respeito aos benefícios econômicos, houve uma redução de $7,8 \%$ no consumo médio de combustível e de 18,7\% no gasto com manutenção do caminhão quando o veículo utilizado na pesquisa percorreu a rota em melhores condições de conservação.

Com relação ao tempo de viagem, apesar de verificada uma economia de quase $2,8 \%$, foi possível notar que as condições da via não são determinantes para resultar num benefício economicamente mensurável. Deve haver outros fatores externos, relacionados às condições da viagem (como tráfego, fiscalização, número de radares, passagem por trecho urbano e velocidade máxima permitida, por exemplo) que podem exercer maior influência no desempenho deste parâmetro.

Os índices de emissões encontrados variaram entre $26,5 \mathrm{~g} \mathrm{CO}_{2} / \mathrm{t}$. $\mathrm{km}$ e $28,5 \mathrm{~g} \mathrm{CO}_{2} / \mathrm{t} . \mathrm{km}$ para rotas melhores e piores, respectivamente, 
Impactos econômicos e ambientais decorrentes do estado de conservação das rodovias brasileiras: um estudo de caso

gerando um benefício de $2 \mathrm{~g} \mathrm{CO}_{2}$ por tonelada transportada a cada quilômetro, ou seja, uma queda de $7 \%$ nas externalidades negativas relacionadas às emissões.

Esta diferença foi essencial para a valoração da externalidade ambiental positiva decorrente de um programa nacional de recuperação das rodovias, a qual deve ser encarada como bastante conservadora (foram adotados os valores correspondentes ao custo de redução das emissões nos países em desenvolvimento, os quais desconsideram os benefícios indiretos).

As análises de sensibilidade indicaram que, no geral, variações percentuais de $10 \%$ provocam variações percentuais menores no valor do benefício total (econômico e ambiental). No caso dos custos variáveis, as variações são mais próximas de $10 \%$, enquanto os outros parâmetros são mais inelásticos. Os custos de manutenção do veículo, entretanto, apresentaram elevada elasticidade, uma vez que uma melhora de $39 \%$ nas condições da rodovia resulta em cerca de $90 \%$ de aumento no valor do benefício total.

No caso dos benefícios ambientais, estes respondem pela menor parcela do valor do benefício total. Conseqüentemente, o preço da tonelada de carbono deve aumentar em 10 vezes para haver um aumento no valor do benefício total de aproximadamente 7,6\% .

Portanto, conclui-se que investimentos em infra-estrutura que melhorem as condições de conservação das rodovias geram benefícios privados e ambientais, os quais, por sua vez, apresentam diferentes impactos nos valores dos benefícios.

A redução do consumo individual de combustível, quando extrapolado para todo o setor de transporte rodoviário de cargas, equivaleria, considerando dados de Lima (2006), a uma queda de 1,7 bilhão de litros consumidos no ano de 2004 e a uma economia de $R$ \$ 2,52 bilhões, contribuindo favoravelmente para a redução nas importações deste combustível bem como para o saldo da balança comercial brasileira.

Espera-se que os resultados obtidos sejam capazes de balizar políticas (via agentes públicos ou privados, ou mesmo através das Parcerias Público-Privadas) que visem o incremento da eficiência do sistema de transporte rodoviário, especialmente do ponto de vista 
econômico e de eficiência energética. Além destes aspectos, é importante também o País identificar soluções sustentáveis que reduzam as emissões de $\mathrm{CO}_{2}$ diante das indefinições atuais referentes ao segundo período de compromisso do Protocolo de Quioto (após 2012), o qual poderá implicar o comprometimento com metas de redução de emissões.

\section{Referências bibliográficas}

ABRIL. Guia 4 rodas. São Paulo. 2004. 1 CD-ROM.

ÁLVARES JUNIOR., O.M.; LINKE, R.R.A. Metodologia simplificada de cálculo das emissões de gases do efeito estufa de frotas de veículos no Brasil. 2003. Disponível em: < http://www.cetesb.gov.br > . Acesso em: 26 abr. 2004.

BARTHOLOMEU, D.B. Potencial da negociação de crédito de carbono a partir da avaliação de trajetos alternativos para uma mesma rota rodoviária: um estudo de caso no Estado de São Paulo. 2001. 95 p. Monografia (Trabalho de Conclusão do Curso de Bacharelado em Ciências Econômicas) - Escola Superior de Agricultura "Luiz de Queiroz", Universidade de São Paulo, Piracicaba, 2001.

BERGER, R. Minimização do custo de transporte de madeira de eucalipto no estado de São Paulo. Piracicaba, 1975. 122 p. Dissertação (Mestrado em Ciências Sociais Rurais) - Escola Superior de Agricultura "Luiz de Queiroz”, Universidade de São Paulo, Piracicaba, 1975.

BRANCO, G.M.; BRANCO, F.C.; MURGEL, E. Modelagem da qualidade do ar em rodovias para a intervenção e gerenciamento da operação. AEA, 2003.

BRASIL. Lei 10.336, de 19 de dezembro de 2001. Institui Contribuição de Intervenção no Domínio Econômico incidente sobre a importação e a comercialização de petróleo e seus derivados, gás natural e seus derivados, e álcool etílico combustível (Cide), e dá outras providências. Diário Oficial, Brasília, 20 dez. 2001. Disponível em: < http://legis. senado.gov.br/sicon/ExecutaPesquisaLegislacao.action $>$. Acesso em: 07 fev. 2006. 
BRASIL. Ministério da Ciência e Tecnologia - MCT; Instituto Alberto Luiz Coimbra de Pós-Graduação e Pesquisa de Engenharia (Coppe). Primeiro inventário brasileiro de emissões antrópicas de gases de efeito estufa: Relatórios de referência e Emissões de Gases de Efeito Estufa por queima de combustíveis; abordagem Bottom-Up. Brasília, 2002a. 110 p.

BRASIL. Ministério da Ciência e Tecnologia e Departamento Nacional de Política Energética. Balanço energético nacional. Brasília, 2005. Disponível em: < http://www.mme.gov.br/site/menu/select_main_menu_ item.do? channelId $=1432$ \&pageId $=4040>$. Acesso em: 29 mar. 2006 .

BRASIL. Ministério da Ciência e Tecnologia. Comunicação nacional do Brasil à Convenção-quadro das Nações Unidas sobre mudança do clima. Brasília, nov. 2004.

BRASIL. Ministério da Ciência e Tecnologia. Primeiro inventário brasileiro de emissões antrópicas de gases de efeito estufa: Relatórios de referência e Emissões de Gases de Efeito Estufa por Fontes móveis, no setor energético. Brasília, 2002b. 105 p.

CENTRO DE ESTUDOS EM LOGÍSTICA (CEL); CONFEDERAÇÃO NACIONAL DOS TRANSPORTES (CNT). Transporte de carga no Brasil: ameaças e oportunidades para o desenvolvimento do país. Rio de Janeiro, set. 2002. Disponível em: < http://www.coppe.ufrj.br > . Acesso em: 1 jun. 2006.

CONFEDERAÇÃO NACIONAL DOS TRANSPORTES (CNT). Boletim econômico. Brasília, jan. 2006. Disponível em: < http://www.cnt.org. br/cnt/downloads/becon/BeconCNT012006.pdf > . Acesso em: 22 jan. 2006.

CONFEDERAÇÃO NACIONAL DOS TRANSPORTES CNT). Boletim estatístico. Brasília, dez. 2005b. Disponível em: < http://www.cnt. org.br/cnt/downloads/becnt/becnt_122005.pdf > . Acesso em: 22 jan. 2006.

CONFEDERAÇÃO NACIONAL DOS TRANSPORTES (CNT). Pesquisa rodoviária 2005: relatório gerencial. Brasília, 2005a. Disponível em: < http://www.cnt.org.br > . Acesso em: 15 abr. 2006. 
CONFEDERAÇÃO NACIONAL DOS TRANSPORTES (CNT). Revista CNT. Brasília, 2001. Vários números. Disponível em: < http://www. cnt.org.br > . Acesso em: 8 mar. 2001.

CONTADOR, C.R. Projetos sociais: avaliação e prática. 3. ed. São Paulo: Atlas, 1997. 375 p.

CORREA JUNIOR, G.M. Principais determinantes do preço do frete rodoviário para transporte de soja em grãos em diferentes regiões brasileiras: uma análise econométrica. 2001. 102 p. Dissertação (Mestrado em Ciências - Economia Aplicada) - Escola Superior de Agricultura "Luiz de Queiroz”, Universidade de São Paulo, Piracicaba, 2001.

FIGUEIREDO, K.F.; FLEURY, P.F.; WANKE, P. (Org.). Logística e gerenciamento da cadeia de suprimentos: planejamento do fluxo de produtos e dos recursos. São Paulo: Atlas, 2003. 488 p.

GHG PROTOCOL INITIATIVE. Calculating $\mathbf{C O}_{2}$ emissions from mobile sources. Disponível em: < http://www.ghgprotocol.org/templates $/$ GHG5/layout.asp?type $=\mathrm{p} \&$ MenuId $=$ OTAx $>$. Acesso em: 15 jun. 2006.

HOFFMANN, R. Estatística para economistas. 2. ed. São Paulo: Livraria Pioneira, 1991. 426 p.

INFORME SIFRECA. Piracicaba, v. 10, n. 111, jul. 2006. Disponível em: < http://sifreca.esalq.usp.br > . Acesso em: 28 jul. 2006.

INTERGOVERNMENTAL PANEL ON CLIMATE CHANGE (IPCC). Revised 1996 IPCC Guidelines for national greenhouse gas inventories. Bracknell, 1997. Disponível em: < http://www.ipcc-nggip.iges.or.jp/ public/gl/invs1.htm > . Acesso em: 2 set. 2004.

LIMA, M.P. Custos logísticos na economia brasileira. Revista Tecnologística. São Paulo, v. 9, n. 122, jan. 2006. Disponível em: < http:// www.coppe.ufrj.br > . Acesso em: 1 jun. 2006.

MÜLLER, F.B. Bolsa de Chicago/EUA realiza primeiro negócio de $\mathrm{CO}_{2} \mathrm{com}$ a Europa. CarbonoBrasil. 9 maio 2005. Disponível em: < http://www. ambientebrasil.com.br/noticias/index.php3?action $=$ ler\&id $=24606>$. Acesso em: 24 jul. 2006. 
PEARCE, D.W.; TURNER, R.K. Economics of natural resources and the environment. 3. ed. Baltimore: The Johns Hopkins University Press, 1994. $377 \mathrm{p}$.

REIS, N.G. Impacto do estado das rodovias sobre o custo operacional dos caminhões. Jan. 2006. Disponível em: < http://www.ntcelogistica.org.br/tecnico/impactorod.asp > . Acesso em: 8 abr. 2006.

SENNA, L.A.S.; MICHEL, F.D.; SAN MARTIN, A.P. et al. Avaliação do impacto da implantação de concessões nas rodovias do Rio Grande do Sul. Porto Alegre: Laboratório de Sistemas de Transportes - LASTRAN/UFRGS, 1998. 188 p.

SINDICATO DAS EMPRESAS DE TRANSPORTES DE CARGAS E LOGÍSTICA NO ESTADO DO RIO GRANDE DO SUL (SETCERGS). Convenção coletiva de trabalho 2005. Disponível em: < http://www.sinecarga. org.br/documentos/aconv2006.doc > . Acesso em: 19 jul. 2006. 